\title{
The Australia (hepatitis-associated) antigen in fibrinogen and other fractions of human plasma
}

\author{
A. J. ZUCKERMAN, PATRICIA E. TAYLOR, R. G. BIRD, AND \\ SUSAN M. RUSSELL
}

From the Department of Bacteriology and Immunology, London School of Hygiene and Tropical Medicine, London

SYNOPSIS Human plasma containing the Australia (hepatitis-associated) antigen was fractionated by the cold ethanol method of Cohn, Strong, Hughes, Mulford, Ashworth, Melin, and Taylor (1946) and small aliquots were examined for the presence of this antigen by immunodiffusion and by electron microscopy. The findings were in general agreement with the postulated risk of transmitting hepatitis by blood derivatives. The Australia (hepatitis-associated) antigen was detected in fibrinogen, thrombin, and antihaemophilic globulin as well as in other fractions. The antigen was not found in gamma globulin (immunoglobulin fraction) nor in albumin.

The use of radioiodinated fibrinogen for the diagnosis of deep vein thrombosis is discussed and it is concluded that the use of fibrinogen for diagnostic procedures should be assessed against the possible risk of hepatitis.

Serum hepatitis and infectious hepatitis now constitute the main hazard of the transfusion of blood and certain blood products (Zuckerman, 1968). Mosley (1965) classified human blood and blood derivatives according to the risk of post-transfusion hepatitis as 'average-risk' materials, which include fresh blood and single donor plasma, 'high-risk' derivatives, which include pooled plasma, fibrinogen, and antihaemophilic globulin, and 'safe' products such as pooled immunoglobulin (gamma globulin) and appropriately treated serum albumin, stable plasma protein solution, fibrin foam, and plasminogen. It should be noted that the risk of hepatitis associated with untreated blood products is independent of the method of fractionation of blood by cold ethanol, by cold ether, or by ammonium sulphate precipitation.

There is extensive epidemiological and immunological evidence for the existence of at least two forms of viral hepatitis and the discovery of the association between the Australia (hepatitis-associated) antigen (Blumberg, Gerstley, Hungerford, London, and Sutnick, 1967) and hepatitis has provided laboratory tests for an antigen which is specifically related to serum hepatitis or type B viral hepatitis (Zuckerman, 1970a). It now appears likely that the Australia (hepatitis-associated) antigen is not the actual infectious agent but that it may Received for publication 18 November 1970. represent incomplete virus particles, or aggregates of protein subunits, or that the antigen is simply a protein which is produced specifically in the liver or at some other site in response to infection by the serum hepatitis virus (Zuckerman, 1970b; Zuckerman, Taylor, and Bird, 1970). Nevertheless, the presence of the antigen in blood and blood fractions may serve as an indicator of potential infectivity with type B viral hepatitis, although the sensitivity of the available techniques does not yield an absolute measure of such risk (Barker, Shulman, Murray, Hirschman, Ratner, Diefenbach, and Geller, 1970; Bulletin of the World Health Organization, 1970). We now report the results of testing for the Australia (hepatitis-associated) antigen by the immunodiffusion technique and by electron microscopy of fractions of human plasma prepared by the cold ethanol method of Cohn, Strong, Hughes, Mulford, Ashworth, Melin, and Taylor (1946).

\section{Materials and Methods}

Human plasma known to contain the Australia (hepatitis-associated) antigen was fractionated by the cold ethanol method of Cohn et al in Sweden by Kabi Ltd, and 18 small aliquots were sent to London for examination. Each sample was tested by the two dimensional micro-Ouchterlony immunodiffusion technique as previously described by Zuckerman and 
Taylor (1969) after the method of Prince (1968). The samples were prepared for examination by negative staining in the electron microscope by the method described in detail elsewhere (Zuckerman, 1970c). It should be noted that antiserum to the Australia (hepatitis-associated) antigen was not added to any of the samples under test.

\section{Results}

The results of the examination by immunodiffusion and electron microscopy are summarized in the Table. No attempt was made to quantitate the

\begin{tabular}{lll}
\hline Product & Immunodiffusion & $\begin{array}{l}\text { Electron } \\
\text { Microscopy }\end{array}$ \\
\hline Whole plasma & & + \\
Supernatant I & + & + \\
Fibrinogen (precipitate I) & + & + \\
First washing from fibrinogen & + & + \\
Second washing from fibrinogen & - & + \\
Residual from last step in fibrinogen & & - \\
precipitation & - & + \\
Cryoprecipitate & - & - \\
Supernatant II & - & - \\
Gamma globulin (fraction II) & - & + \\
Supernatant II + III & + & - \\
Thrombin (precipitate III) & + & + \\
Supernatant IVa & - & - \\
Precipitate IVa & - & + \\
Supernatant IVb & - & - \\
Precipitate IVb & - & - \\
Supernatant IV + V & - & - \\
Supernatant V & - & - \\
Albumin (precipitate V) & - & \\
\hline
\end{tabular}

Table The Australia (hepatitis-associated) antigen in plasma and plasma fractions

number of antigen particles visualized by electron microscopy in individual samples (Fig. 1) but a rough estimate indicates that fractionation resulted in an increase in the number of particles of the Australia (hepatitis-associated) antigen in the supernatant of fractions I and III (Fig. 2). It is noteworthy that the number of particles found by electron microscopy was greater in thrombin and in precipitates IVa and IVb than in fibrinogen (Fig. 3). However, both the first and second washings of fibrinogen contained numerous antigen particles strongly suggesting, first, that the antigen is present in considerable quantity in fibrinogen, and secondly that more extensive washing of fibrinogen may remove most of the antigen. The morphological entities representing the Australia (hepatitis-associated) antigen were not detected in gamma globulin (immunoglobulin) nor in unheated albumin (precipitate V). Finally, the results indicate that examination of selected specimens by electron microscopy is a more sensitive technique than immunodiffusion for the detection of the Australia (hepatitis-associated) antigen.

\section{Discussion}

Our findings are virtually in accord with the postulated risk of hepatitis which had been estimated by Mosley (1965). The Australia (hepatitis-associated) antigen was not detected in the gamma-globulin (immunoglobulin) fraction nor in unheated albumin. The antigen particles may have been removed from these fractions by physical separation or alternatively our techniques are not sensitive enough to demonstrate small quantities of the antigen nor other particles which may cause the infection. Unheated human albumin has been shown by volunteer experiments to be icterogenic but albumin heated at $60^{\circ} \mathrm{C}$ for 10 hours is apparently free of the risk of transmitting hepatitis (summarized by Maycock, 1965).

The morphological entities associated with the Australia (hepatitis-associated) antigen were, however, found in fibrinogen, thrombin, and antihaemophilic globulin, all of which have been implicated in the transmission of serum hepatitis. Essentially similar observations have been recorded by Schroder and Mozen (1970) and also by Holland, Alter, Purcell, and Sgouris (1970) who employed the radioimmunoassay technique in addition to immunodiffusion and complement-fixation.

In the past the assessment of risk involved in the use of fibrinogen proved difficult because fibrinogen is generally given with whole blood. Attack rates of 14 to $15 \%$ were reported by Phillips (1965) and $17 \%$ by an expert committee (WHO, 1964). In two university hospitals in the United States it was estimated that the proportion of fibrinogen recipients amongst patients with transfusion-associated hepatitis was 35 times greater than amongst patients transfused with blood only (Mosley, 1965). Only rarely does a situation arise, apart from specific deficiency of fibrinogen or antihaemophilic globulin, in which fibrinogen is required without a need for blood or plasma as well. Mosley (1965) mentions the occurrence of hepatitis in six of 21 patients following the administration of fibrinogen alone. The more recent introduction of radioiodinated fibrinogen ${ }^{\left({ }^{125} I\right)}$ for the diagnosis of deep vein thrombosis (Browse, 1969) has introduced a new risk. The enthusiastic use of ${ }^{125}$ I-fibrinogen for diagnostic procedures should be assessed against the possible risk of hepatitis. Indeed serum hepatitis associated with the Australia antigen has already been reported in two patients from the west of Scotland who had been injected with ${ }^{125}$ I-fibrinogen (Laiwah, Goudie, Goldberg, Davidson, and Murray, 1970).

The availability of specific serological methods in 


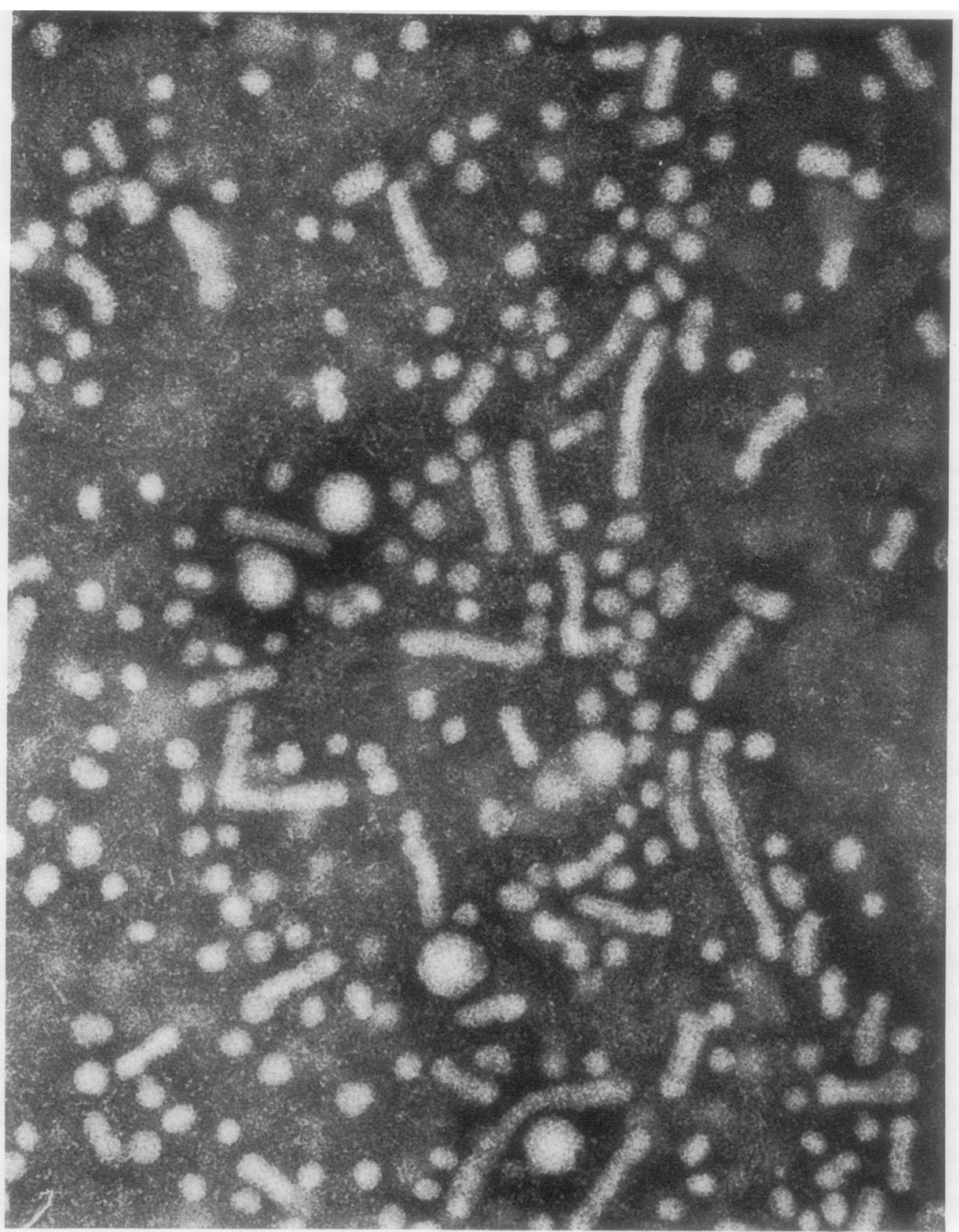

Fig. 1 Whole plasma showing the three typical morphological entities identified with the Australia (hepatitisassociated) antigen: small pleomorphic spherical particles measuring approximately $20 \mathrm{~nm}$ in diameter, the long tubular forms, and large solid spheroidal particles measuring 40-45 nm in diameter. $\times 190,000$. 


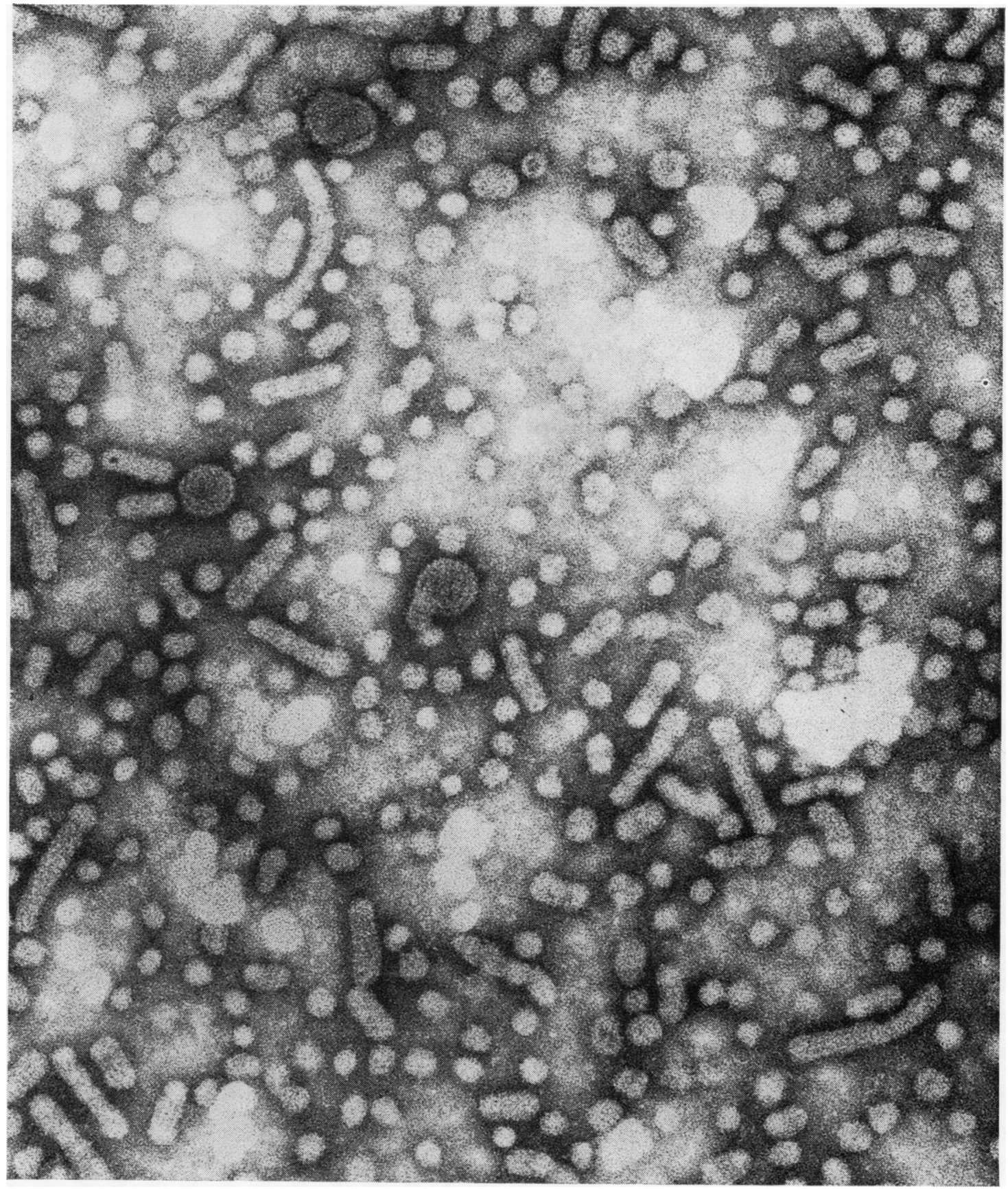

Fig. 2 Numerous particles were present in the supernatant from Cohn fractions II + III (the particles were not found in the supernatant of fraction II alone). $\times 190,000$. 


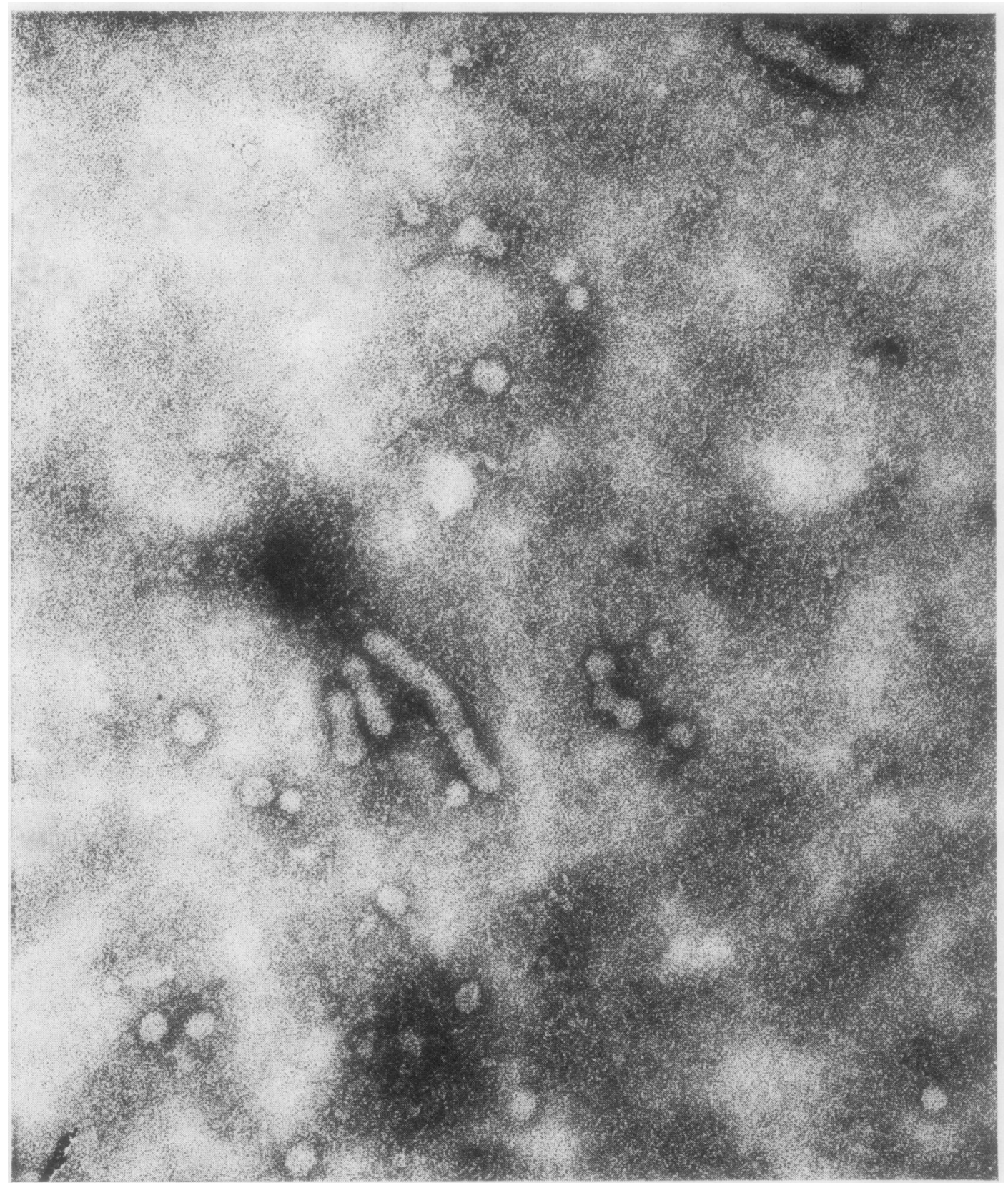

Fig. 3 Scattered particles were present in fibrinogen (precipitate I). These particles display the typical morphology of the Australia (hepatitis-associated) antigen. $\times 190,000$. 
testing for the Australia (hepatitis-associated) antigen and the application of these techniques to the diagnosis and prevention of at least a proportion of cases of viral hepatitis associated with the transfusion of blood and blood products is now a practical possibility. The identification and exclusion of carriers of the Australia (hepatitis-associated) antigen in blood donors by screening programmes and the application of test procedures to donated blood and to individual units of plasma used for processing plasma fractions is thus an urgent need. It should be borne in mind, however, that there are limitations to the currently available methods and that none of the reagents nor the techniques have yet been standardized.

It is a pleasure to acknowledge the interest and help of Dr S. Akerfeldt, Research Department of the Kabi Group, Stockholm. This work was supported by a generous grant from the Medical Research Council to A.J.Z.

\section{References}

Barker, L. F., Shulman, N. R., Murray, R., Hirschman, R. J., Ratner, F., Diefenbach, W. C. L., and Geller, H. M. (1970). Transmission of serum hepatitis. J. Amer. med. Ass., 211, 1509-1512.

Blumberg, B. S., Gerstley, B. J. S., Hungerford, D. A., London, W. T., and Sutnick, A. I. (1967). A serum antigen (Australia antigen) in Down's syndrome, leukemia and hepatitis. Ann. intern. Med., 66, 924-930.

Browse, N. (1969). Deep vein thrombosis. Brit. med. J., 4, 676-678.
Bulletin of the World Health Organization (1970). Memorandum. Viral hepatitis and tests for the Australia (hepatitis-associated) antigen and antibody. 42, 957-992.

Cohn, E. J., Strong, L. E., Hughes, W. L., Jr., Mulford, D. J., Ashworth, J. N., Melin, M., and Taylor, H. L. (1946). Preparation and properties of serum and plasma proteins. IV. A system for the separation into fractions of the protein and lipoprotein components of biological tissues and fluids. J. Amer. chem. Soc., 68, 459-475.

Holland, P., Alter, H. J.. Purcell, R., and Sgouris, J. (1970). Personal communication.

Laiwah, A. C. Y., Goudie, R. B., Goldberg, D. M., Davidson, J. F., and Murray, T. S. (1970). Australia antigen in West of Scotland and North of England. Lancet, 2, 121-123.

Maycock W. d'A. (1965). Control of serum hepatitis. In European Symposium on Viral Hepatitis, pp. 82-95. WHO, Copenhagen.

Mosley, J. W. (1965). The surveillance of transfusion-associated viral hepatitis. J. Amer. med. Ass., 193, 1007-1010.

Phillips, L. L. (1965). Homologous serum jaundice following fibrinogen administration. Surg. Gynec. Obster., 121, 551-556.

Prince, A. M. (1968). An antigen detected in the blood during the incubation period of serum hepatitis. Proc. nat. Acad. Sci. (Wash.), 60, 814-821.

Schroeder, D. D., and Mozen, M. M. (1970). Australia antigen: distribution during Cohn ethanol fractionation of human plasma. Science, 168, 1462-1464.

World Health Organization (1964). Wld Hlth Org. techn. Rep. Ser., 285.

Zuckerman, A. J. (1970a). Immunological aspects of viral hepatitis. In Symposium on Advanced Medicine, edited by J. D. H. Slater, pp. 133-140. Pitman, London.

Zuckerman, A. J. (1970b). Recent advances in viral hepatitis. Abstr. Hyg., 45, 857-862.

Zuckerman, A. J. (1970c). Electron microscopy and immune electron microscopy. Bull. Wld Hlth Org., 42, 975-978.

Zuckerman, A. J., and Taylor, P. E. (1969). Persistence of the serum hepatitis (SH-Australia) antigen for many years. Nature (Lond.), 223, 81-82.

Zuckerman, A. J., Taylor, P. E., and Bird, R. G. (1970). Antigens and viruses in acute hepatitis. Clin. exp. Immunol., 7, 439-452. 